has made important contributions to public health or profit. These concern especially the control of insect pests by chemical means and the development of new techniques for baiting rodents and, more recently, the development of anti-coagulant poisons. Perhaps characteristically in Britain, the pioneer work was done in the universities and received final Government blessing during the Second World War. There is a useful list of papers published by members of the infestation control division during the past fifteen years.

\section{Nitrogen Replenishment in the Soil}

LAND fertility improvement was the theme of the presidential address by Dr. N. R. Dhar, of the University of Allahabad, this year to the Indian Society of Soil Science held at Delhi. He points out that the amount of fertilizer used in the world is still very inadequate and production of nitrogen fertilizer appears to be lagging behind production of phosphate and potash. Under-developed countries are poorly equipped with nitrogen-fixation factories because of the high capital investment involved. Dhar estimates that approximately one hundred million tons of fixed nitrogen is necessary for the food supply of the world, but present production is less than eight million tons. This emphasizes the importance of other nitrogen sources. For example, legumes probably fix five million tons of nitrogen and rain contains about ten million tons. It is also pointed out that the amount of nitrogen lost in refuse from urban areas is about equivalent to the amount of nitrogen supplied to world crops as fertilizer. Even in highly organized agriculture such as in the United States, more nitrogen is removed from the soil than returned as fertilizer, resulting in an annual deficit of six million tons. This translated into world figures means a loss of about fifty million tons of nitrogen a year. This annual loss must be compensated in permanent agriculture by natural methods of recuperation. By making assumptions concerning the amount of carbon added to the earth by photosynthesis and the proportion of this which in turn is oxidized, it is estimated that one hundred and ten million tons of nitrogen a year is fixed by natural processes. Hence this is the chief natural source of soil nitrogen and far exceeds the amount supplied by fertilizers.

\section{Tectonics in the U.S.S.R.}

A GReAT advance in tectonics was made by the publication of the tectonic map of the Soviet Union in 1957 on the scale of $1: 5,000,000$, published on nine sheets. This map is coloured vividly in accordance with the orogenic age of the formations, with tints and shadings indicating various folding phases and structural features. The map was compiled by a number of geologists under the direction of N. S. Shatsky, one of tho foremost tectonists in the Soviet Union. It was accompanied by an explanatory memoir written by N. S. Shatsky and A. A. Bogdanov. A small-sized variant of this map is published by Y. A. Kosygin (Priroda, 8, $21: 1958$ ) as an illustration for his article dealing with new methods applied to the study of tectonic structure of the Earth's crust by means of deep stratigraphical boreholes. This method, according to the author, is particularly suitable for the study of the 'cover' of ancient 'platforms' and also for the preparation of 'palæogeological' maps of the 'floor' of the 'cover'. In another article Y. A. Meshcheryakov (Priroda, 9, 15; 1958) diseusses 'neotectonics'-..a term proposed by V. A. Obruchev for the study of the recent or near-recent movements of the Earth's crust. In this article he gives a 'neotectonic' map of the European part of the Soviet Union and a generalized map of the world showing regions of recent elevation and depression as well as the earthquakes zones. This map shows that the modern regions of elevation are not confined to the areas of Quaternary glaciation and therefore cannot be explained by the hypothesis of glacial isostasy control.

\section{Meteorological Data}

RADAR is a powerful tool for the meteorologist in the detection of precipitation as it is the only means of locating the positions of all precipitation falling at above a certain moderate rate and at any one time within a distance of the order of 100 miles from the transmitter. The strength of the radar echo is proportional to $N D^{8} / L^{4}$, where $N$ is the number of drops in unit volume, $D$ the drop diameter and $L$ the wavelength of the radar. The echo intensity thus increases very rapidly with the size of the drops. The advantage of a very short wave-length is, however, offset by increased attenuation of the beam by precipitation. and the water vapour and oxygen of the air, and by engineering difficulties of obtaining adequate radiant power. In practice, wave-lengths in the region of $3-10 \mathrm{~cm}$. are mostly used, giving admirable representation of moderate and heavy rain at distances up to 100 miles or more. Radar is of great value for guiding aircraft in and out of airfields to avoid highly turbulent thunderclouds, in forecasting the approach to cities of thunderstorms with their effects on public transport and demand for lighting, and also in the study of cloud structure and hydrology. The subject is comprehensively discussed in all its aspects in a recent report by the World Meteorological Organization prepared by a Working Group of the Commission for Instruments and Methods of Observation under the chairmanship of Mr. R. F. Jones, of the Meteorological Office (Technical Note No. 27: Use of Ground-Based Radar in Meteorology (Excluding Upper-Wind Measurements). Pp. xvi +80 . Geneva: Secretariat of the World Meteorological Organization, 1959. 9 Swiss franes). This describes the basic theory, types of radar and display, recording and transmitting the information, the types of radar echo associated with clouds and precipitation, echoes from other phenomena such as smoke, insects and birds, the practical applications and the use of radar in research.

\section{European Nuclear Energy Project, Dragon}

Three engineers, one from Switzerland and two from Italy, arrived in Britain on September 21, representing the advance guard of some ninety European engineers and scientists who, with 160 from the United Kingdom, will comprise the international staff of the Dragon project of the Organization for European Economic Co-operation at the Atomic Energy Establishment, Winfrith, Dorset (see Nature, 183, 507; 1959).

\section{Harwell Reactor School Courses}

STANDaRd Course No. 20 of the Harwell Reactor School will commence on January 4 and continue until April 29, 1960. These courses, which began in September 1954, are designed to train engineers 